\title{
1) \\ O PENSAR CRIATIVO - O PROCESSO CRIATIVO E O ENSINAMENTO DAS CORES
}

\author{
THE CREATIVE THINKING - THE CREATIVE PROCESS AND THE TEACHING \\ OF COLORS
}

Dulce Maria Holanda Maciel (CEART/DMO) dulceholanda@gmail.com Fabiana Ludwig dos Santos(CEART/DMO) fabiludwig@hotmail.com Schirlei Martins O. San Romãn (Bolsista PIBIC/Cnpq) schirlei.ortega@gmail.com

Resumo

Este texto relata uma experiência no aprendizado sobre cores realizada na disciplina intitulada Fundamentos da cor do curso de Design de Moda do CEART/UDESC no ano de 2012. O grande desafio estabelecido na disciplina foi ensinar os conceitos básicos relativos a cores, suas características, usos, círculo cromático e esquemas harmônicos. No começo da disciplina foram estabelecidas as tarefas e o aporte teórico o qual envolveu o processo criativo e o ensinamento das cores através de exercícios desenvolvidos em sala de aula. Este texto demonstra uma breve apresentação do trabalho desenvolvido no semestre.

Palavras-chave: Criatividade. Cor. Ensino.

Abstract

This article reports an experience in learning about colors held in the subject entitled Color Funtamentals of Fashion Design course of CEART/UDESC in 2012. The challenge established in the subject was teaching the basic concepts about colors, its characteristics, uses, chromatic circle and harmonic schemes. In the subject's beginning, the tasks and the theoretical framework that involved the creative process and the teaching of colors through exercises developed in class were established. This text shows a brief presentation of the work developed during the semester.

Keywords: Creativity. Color. Teaching.

\section{INTRODUÇÃO}

O presente trabalho relata a experiência desenvolvida na disciplina Fundamentos da Cor do curso de Design de Moda do Ceart no ano de 2012. O trabalho envolveu várias etapas: a confecção de um círculo cromático, o estudo das cores primárias, secundárias e terciárias, e a diferenciação das 


\section{ע|}

temperaturas de cor. Todos os itens, passando pela pesquisa da simbologia das cores e apontando aspectos por vezes ocultos na utilização de determinada cor, culminaram com a apresentação de croquis com desenhos de vestuário envolvendo uma cartela de cores desenvolvida pelo aluno seguindo orientação dos professores para montagem dos esquemas harmônicos. O estudo do processo criativo com a definição das etapas de afetividade, processo metacognitivo e criatividade, foi o item focal e que serviu como aporte teórico para os exercícios propostos na disciplina e descritos a seguir.

\section{O PROCESSO CRIATIVO}

Munari (1975) destaca o pensar criativo como um dos pilares do processo de aprendizagem. Explica que o pensar criativo envolve uma forma de agir especifica para alcançar um objetivo, neste o pensamento não obedece a regras, aceita diferentes conceitos, mas em todos os casos percorre um caminho para o resultado.

O autor discorre sobre determinados tipos de barreiras encontradas no processo criativo:

- Medo do fracasso - ressalta-se aqui a simples possibilidade de não atingir o êxito como inibição do processo criativo, esquivando-se da frustração;

- Falta de recursos;

- Falta de tempo;

- Falta de oportunidade em realizar atividades fora da sala de aula.

O autor cita que a criatividade também é utilizada como ferramenta auxiliar no ensino de outras disciplinas como matemática, história ou física, usando-se conceitos relativos a cada tema, bem como auxilia o aluno a explorar e descobrir novos cenários e enfatizar a interdisciplinaridade. 


\section{Rerysta \\ A APOTHEKE}

$\mathrm{Na}$ aprendizagem das cores vale citar Dewey (1971) que defendia o princípio no qual os alunos aprendem melhor realizando tarefas associadas aos conteúdos ensinados. Neste ponto salienta-se que o ensino das cores esbarra de início no seu preceito mais básico - o entendimento da física de reflexão da luz e na anatomia humana e suas regras de formação de imagens.

Desta forma é essencial inicialmente propor uma reflexão a partir das leis físicas e biológicas que formam as cores, chegando rapidamente à classificação de cores primárias, secundárias, complementares, suas características e esquemas cromáticos.

Como recurso utilizado para envolver os alunos no processo de aprendizagem sobre as cores e também promover a motivação necessária para o entendimento sobre sua influência, foi realizada a apresentação da teoria das cores seguindo os três patamares da criatividade citados por Schlochauer (2007) o qual divide o processo criativo em: afetividade, processo metacognitivo e o processo criativo.

\section{Primeiro patamar - afetividade}

Schlochauer (2007) afirma que a afetividade é a base de qualquer aprendizagem. Munari (1975) também já contextualizava a importância do desenvolvimento afetivo do sujeito criador pelo objeto produzido.

Um dos principais aspectos do processo de aprendizagem é a afetividade e diz respeito a aprender a aprender.

o autor conclui que o estado emocional pode facilitar e/ou acelerar a integração de novas informações, reestruturando esquemas mentais.

Andrade (2009) cita Dewey que propõe um sistema de educação baseado na experimentação. Assim, considerando que uma aula é um microssistema onde existem regras, valores, 


\title{
\|
}

atitudes a respeitar e relações de poder, também devem existir objetivos claros da forma de aquisição de conteúdos pelos alunos e a competência em gerir os recursos didáticos e distribuição de tempo pelo professor.

O papel contagiante das emoções está presente no modelo sócio pedagógico de J. Dewey (1954) enfocando o aprendizado através do desenvolvimento da autoestima e da personalidade dos educandos.

\begin{abstract}
Torna-se importante ressaltar a diferença entre sentimento e emoção. A emoção possibilita mudança na condição física enquanto que o sentimento não apresenta manifestações físicas ou fisiológicas tangíveis. Quando temos um sentimento, temos controle, já as emoções são mais contagiantes, são verdadeiras desencadeadoras de epidemia mental. (ALMEIDA; SEMINERIO, 2005, p. 13)
\end{abstract}

Saiani citado em Almeida e Seminerio (2005) nos relata que - relacionamento entre o professor e seu aluno desempenha importante papel na criação deste 'clima de aula'. Aqui completa que 'a sala de aula' é o terreno onde os pequenos acontecimentos acontecem todos os dias. As alegrias, tristezas, olhares e queixas. Almeida e Seminerio (2005, p. 15) comentam que se deve deixar fluir uma atmosfera favorável entre professor e alunos. Propõem ao professor atenção ao seu próprio estado mental a fim de verificar de onde provem as dificuldades que encontra no processo de ensino-aprendizagem. Salienta ainda que esta atmosfera favorável é mais importante que qualquer método ou técnica utilizada em sala de aula.

Assim, o desafio de organização do conteúdo respeitou a lógica necessária para a construção do conhecimento a ser atingido sobre os processos harmônicos da cor.

A apropriação do conhecimento por parte do aluno foi proposta a partir de atividades motivadoras. O exercício inicial foi elaborado para pôr em prática um vínculo inicial que envolvesse afetividade. A primeira parte do exercício foi propor a cada aluno a escolha de uma cor favorita e sua 


\section{《I}

descrição em termos estéticos, subjetivos, com ênfase nas emoções relacionadas ao uso desta cor e outros pontos que julgassem importantes. Foi proposto o uso desta cor escolhida para realizar os exercícios de dessaturação, como exemplificados nas imagens 1 e 2, cores primárias, complementares e análogas. A pesquisa envolvendo sua cor favorita deixou clara as implicações pedagógicas do vínculo emocional desejado dos alunos com a disciplina.

Figura 1 - Exercício de rebaixamento da cor violeta.

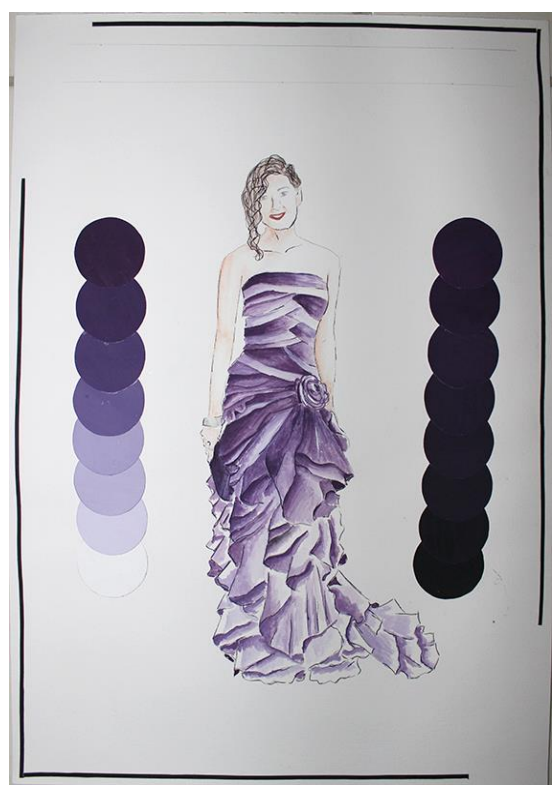

Caderno de exercícios da aluna Schirlei Martins.

A aluna continuou usando a cor favorita - violeta - para a realização do exercício de dessaturação demonstrado a seguir.

Figura 2 - Exercício de dessaturação da cor violeta. 


\section{REVISTA}

APOTHEKE

\section{DESSATURADO}

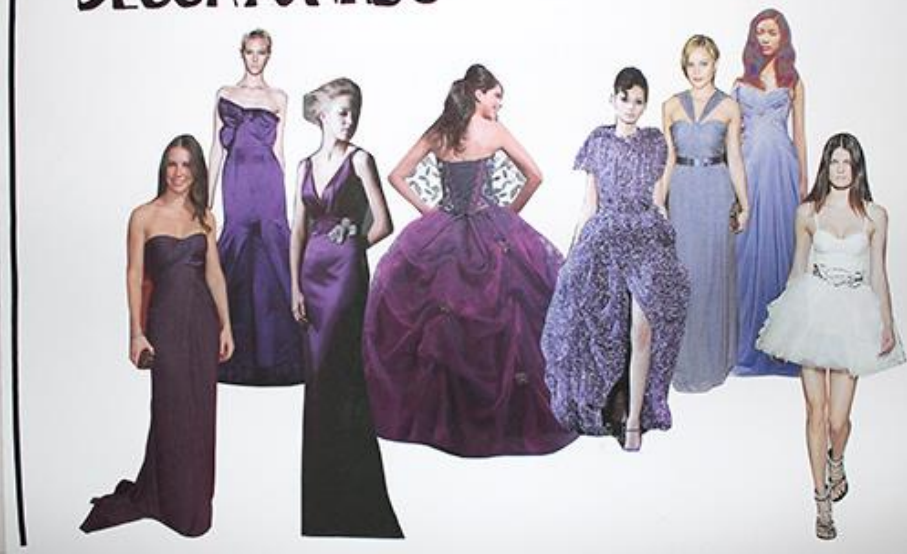

Caderno de exercícios da aluna Schirlei Martins.

\section{Segundo patamar - o processo metacognitivo}

Minsky (1989) já nos alertava que o processo mental de aprendizagem inclui estratégias cognitivas, metacognitivas e de administração de recursos.

Como estratégias cognitivas pode-se citar as estratégias de memorização - repetição, por exemplo, elaboração e transformação. As metacognitivas incluem um controle e regulação do próprio processo de aprendizagem.

Neste caso existe a escolha do que aprender envolvendo a atitude de decisão no avanço ou desistência da tarefa.

Os conhecimentos metacognitivos são construídos e transformados através de experiências conscientes.

A metacognição diz respeito, entre outras coisas, ao conhecimento do próprio conhecimento, à avaliação, à regulação e à organização dos próprios processos cognitivos. (RIBEIRO, 2003, p. 111)

Implica em um processo, ou seja, uma elaboração, uma organização, um ambiente de estudo, e tempo para desenvolver ideias, resumindo ações planificadas. Aqui o aluno é o conhecedor de si próprio como atuante no processo de aprendizagem e também o é como processador de informações, 


\title{
\|
}

colaborando assim com o posicionamento de Dewey que defendia a importância do crescimento - físico, emocional e intelectual dos alunos durante o processo de aprendizagem.

Este posicionamento dá ênfase a independência dos alunos em administrar os recursos com as estratégias que melhor se adéquam aos seus objetivos, aprendendo melhor realizando tarefas associadas aos conteúdos ensinados. Em resumo a metacognição implica em uma série de operações mentais que dirigem e controlam a produção dos significados. Baseada em um mecanismo de experiências pessoais e da relação com os outros, - aluno tem a capacidade de alterar sua conduta objetivando suas próprias metas de aprendizado.

\begin{abstract}
A metacognição envolve um processo recursivo que não pode ser apartado do processo imaginário, pois as imagens subjazem a qualquer processo mental. Refletir, planejar, organizar estratégias, usar o conhecimento previamente adquirido, acessar informações relevantes, tudo isto está impregnado de imagens que levam a um processo criativo. (ALMEIRA; SEMINEIRO, 2005, p.11)
\end{abstract}

A partir da escolha e do conhecimento das características e emoções envolvidas em cada cor, foi realizada a segunda parte do exercício. Ao aluno foi proposto a escolha de uma imagem na qual a cor estudada anteriormente fosse a dominante para realizar diversas tríades. Cabe ressaltar que o aluno montou a partir de uma tríade de cores os esquemas cromáticos que mais lhe agradassem, sem contar com nenhuma técnica explicita, apenas sua intuição. Nas imagens 3 e 4 pode-se observar o exercício de composição a partir da escolha de tríades de cores análogas.

Figura 3 - Exercício de tríades análogas I. 


\section{X)}

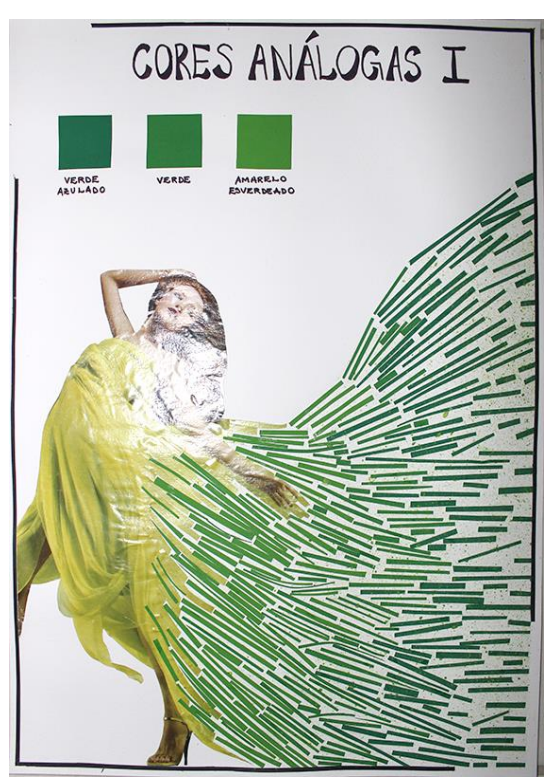

Caderno de exercícios da aluna Schirlei Martins.

Figura 4 - Exercício de tríades análogas II.

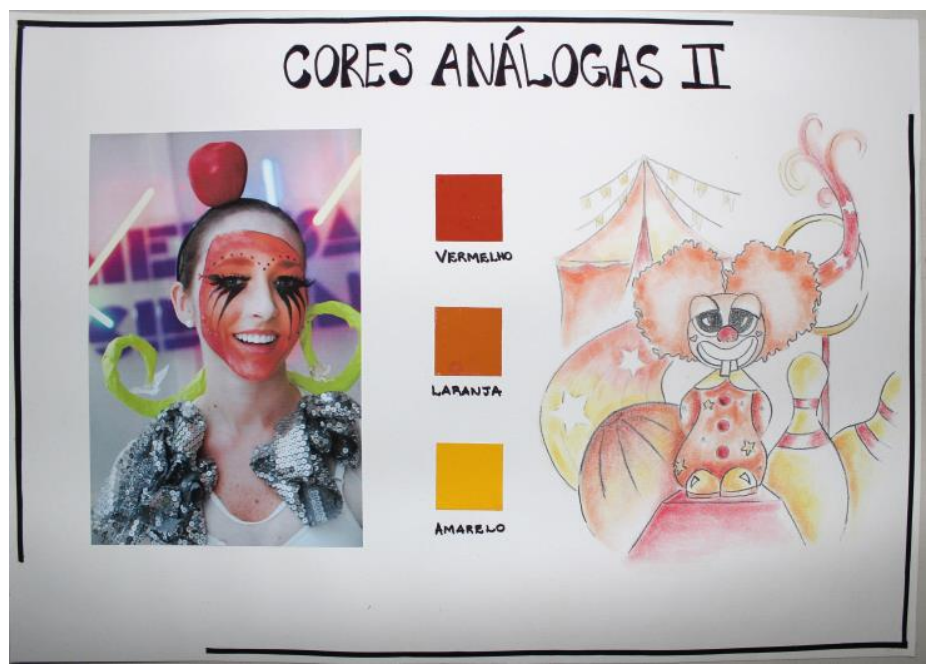

Caderno de exercícios da aluna Schirlei Martins.

A ideia de conceber um exercício inusitado baseado na intuição e espontaneidade considerando fatores antes não vivenciados norteou o exercício marcado por sentimentos, pensamentos, intelecto, expressão e construção.

Terceiro patamar - o processo criativoSchlochauer (2007, p. 251) define algumas características do processo criativo: 


\section{U.}

- Criatividade - produto do gênio humano como gerador de novas ideias, conceitos e teorias;

- Invenção - processo no qual delineia um produto, processo ou protótipo resultante da combinação de ideias onde pelo menos uma delas é inteiramente nova;

- Inovação - é a transformação de ideias em aplicações uteis.

o autor continua citando que o grande objetivo da criatividade é encontrar e resolver problemas de forma inovadora (novos ambientes e situações) representando uma certa ação de transgressão (patenteada na liberdade de pensamento). Refere-se à criação como o aparecimento real de uma coisa, de uma obra que não existia antes por uma ação deliberada e consciente de um ser.

Vários autores estudam a criatividade, e a agrupam. Taylor (1976) conceitua cinco tipos de criatividade:

- Expressiva - a pessoa expressa seus sentimentos de modo criativo - o foco é a catarse emocional. Improvisação teatral;

- Produtiva - a criação está restrita a certas condições metodológicas. o foco é a produção da obra. Investigação cientifica;

- Inventiva - unem-se características expressivas e produtivas para produtos inéditos e inesperados. Lâmpada elétrica;

- Inovadora - mais do que a criação de obras, este tipo situa-se no campo da transformação criativa de teorias e concepções. Einstein;

- Emergente - dos gênios. Criatividade natural e espontânea que se aplica em todos os campos. Leonardo da Vinci; 


\section{《)}

Já Kneller (1978) apresenta as seguintes teorias

filosóficas sobre criatividade:

- Inspiração divina, ao invés da educação;

- Como forma de loucura, em virtude da espontaneidade e irracionalidade;

- Como gênio intuitivo associada a pessoas raras e diferentes;

- Como força vital numa manifestação do processo organizador presente em toda vida;

- Como força cósmica, expressão da criatividade universal inerente a tudo que existe.

Apenas recentemente tem havido uma quebra de vínculo entre criatividade e poder divino. O termo criatividade é frequentemente associado ao elemento novidade - é considerado criativo aquilo que gera novas informações entre situações (objetos, informações) que antes não possuíam relações. É observar um problema sob um ponto de vista inteiramente novo e propor uma solução inovadora, curiosa e inusitada.

Predebon (1998) cita ainda que as ideias criativas são com frequência o produto de uma associação de duas referências aparentemente estranhas entre si.

- processo criativo está associado a Engenharia do Conhecimento, que considera a mente como um sistema de inferências - o que pressupõe a existência de estruturas obtidas por combinações conceituais e de informação usando representações através da organização de blocos coerentes e previamente existentes.

A imaginação é a primeira característica da criatividade, e está ligada ao raciocínio. A imaginação e a memória andam lado a lado já que a primeira está vinculada a nossa capacidade de modificar o mundo e transformar a realidade para criar algo novo. 


\section{A $\mid$ REVISTA}

Segundo Rubinstein (1973) apud SCHLOCHAUER (2007, p. 253) a diferença entre imaginação e memória consiste no fato de que a relação das imagens reproduzidas da memória é distinta da relação da imaginação com a realidade objetiva. O fato comum destes dois processos é a criação e formação de uma ideia imaginativa unitária, culminando com uma representação. Assim, a percepção e a atenção, a memória e a imaginação, a consciência e a ação deixam de ser consideradas como propriedades mentais simples, eternas e inatas, começando a entenderem-se como produtos de formas sociais complexas em relação aos processos mentais.

Usar a imaginação e a memória foi imprescindível para a resolução da última e terceira parte do exercício proposto - o painel de esquemas cromáticos.

Realizado a partir da afetividade - cor favorita, da cognição e imaginação na realização dos esquemas cromáticos a confecção do painel cromático teve como finalidade a realização de tríades cromáticas a partir da escolha de três cores retiradas do painel imagético.

Figura 5: Esquema cromático proposto.

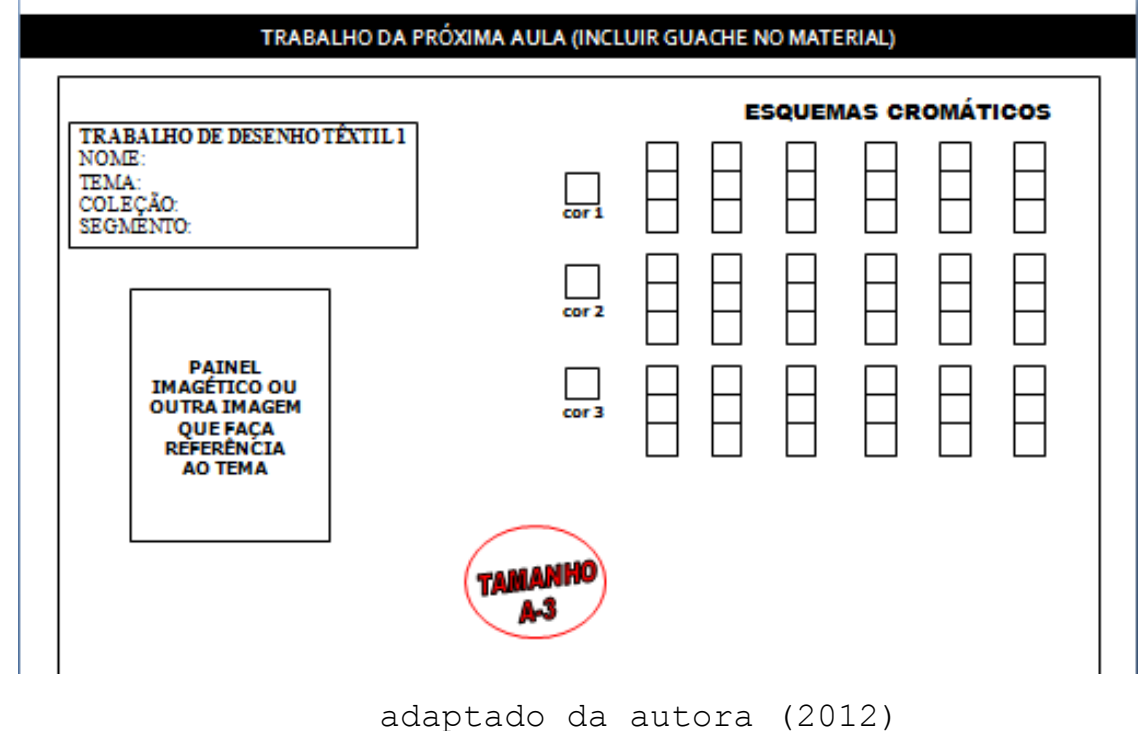

ISSN: 2447-1267 Santa Catarina, v.2, n.2, ano 2, fevereiro de 2016. 


\section{R| Revrsta \\ A APOTHEKE}

Os alunos que são incentivados a trabalhar a partir das suas áreas de interesse captam e desenvolvem competências importantes em cada uma das disciplinas combinando seus próprios interesses e processos de pensamento criativo.

É uma atitude de motivação intrínseca. Tendo assim um estado de total absorção de conteúdos, o fato de estar imerso numa atividade tão satisfatória faz com que o participante perca a noção do tempo, do cansaço e todo o resto focando na atividade.

Para um ato criativo acontecer as emoções desempenham um importante papel, a atividade da imaginação é uma descarga de emoções, de sentimentos, devemos assim a considerar em todas as etapas do processo de aprendizagem.

\section{CONCLUSÕES}

As áreas cerebrais responsáveis pela percepção visual e imaginação são as mesmas, desta forma o estimulo é simultâneo e básico para o processo criativo.

A arte estimula a comunicação não verbal através da linguagem visual, corporal ou musical estimulando os indivíduos a expressar suas ideias sobre si e o mundo que o rodeia. Ela ainda objetiva o autoconhecimento, desenvolvendo a autoconfiança e o sentido de autoestima por ser um instrumento de autodescoberta, e desenvolve a percepção visual e auditiva na medida em que expande a organização espacial e a discriminação sonora e visual. A arte também desenvolve integralmente a pessoa, pois unifica a maioria dos aspectos da personalidade.

O ponto comum observado na maioria dos textos que abordam criatividade explicita que o processo criativo envolve na sua grande maioria uma atualização constante e permanente de informação. Desta forma fica clara a necessidade de uma 


\section{VI}

pesquisa aprofundada em todas as fases de criação da solução de um problema.

Para o design a solução do processo criativo resulta na resposta ao problema proposto expresso através do projeto de produto, uma etapa do trabalho do designer.

o objetivo aqui é forçar um olhar diferente, um pensamento lateralizado, ou seja, divergente do tradicional, um olhar sobre outras possibilidades, treinando a própria mente a se tornar criativa.

\section{REFERÊNCIAS BIBLIOGRÁFICAS}

ALMEIDA, N. F.; SEMINERIO, F. L. P. Cognição e Emoção: a importância do imaginário para a metacognição e a educação. In. LIBÂNEO, J. C.; SANTOS, A. (Org.) Educação na era do conhecimento em rede e transdisciplinaridade. [S. 1.]: Alinea, 2005 .

DEWEY, J. Experiência e educação. Tradução: Anísio Teixeira. [S. 1.]: Companhia Editora Nacional, 1971.

DEWEY, J. Meu credo pedagógico. In. D'ÁVILA, Antônio.

Pedagogia. São Paulo: Companhia Editora Nacional, 1954.

KNELLER, G. F. Arte e ciência da criatividade. 5. ed. São Paulo: Ibrasa, 1978 .

MINSKY, M. A sociedade da mente. Rio de Janeiro: Francisco Alves, 1989 .

MUNARI, B. Diseño y comunicación visual. Barcelona: Gustavo Pili, 1975.

PREDEBON, J. Criatividade - abrindo o lado inovador da mente: um caminho para o exercício prático dessa potencialidade, esquecida ou reprimida quando deixamos de ser criança. 2 . ed. São Paulo: Atlas, 1998.

RIBEIRO, C. Metacognição: um apoio ao processo de aprendizagem. Psicologia: Reflexão e Crítica, [online] v. 16, n. 1, p. 109-116, 2003. Disponível em

<http://www.scielo.br/pdf/prc/v16n1/16802.pdf>. Acesso em 26 out. 2015 . 


\section{REVISTA}

APOTHEKE

SCHLOCHAUER, C. Desenvolvimento da criatividade em estudantes universitários: uma análise de estratégias de ensino. 2007. Projeto de pesquisa para processo de seleção (Doutorado em Psicologia Escolar e do Desenvolvimento Humano) - Universidade de São Paulo, São Paulo, 2007. Disponível em

<http://cappf.org.br/tikidownload wiki attachment.php?attId=37>. Acesso em 28 fev. 2011.

TAYLOR, C. W. Criatividade: progresso e potencial. 2. ed. São Paulo: Ibrasa 1976.

\section{Dulce Maria Holanda Maciel}

Doutora em Engenharia de Produção com ênfase em Gestão de Design, Ergonomia e Meio Ambiente pela UFSC (2007); Mestre em Engenharia de Produção com ênfase em Gestão Ambiental pela UFSC (2002); Bacharel em Engenharia Elétrica pela UFSC (1986); Pós-Graduação em Design de Moda pela Universidade Estácio de Sá - SC (2011). Bacharel em Moda pela UDESC (2011). dulceholanda@gmail.com

Fabiana Ludwig dos Santos

Mestre em Educação, Comunicação e Tecnologia pela UDESC (2010); Pós-Graduação em Moda - Criação e Produção de Moda pela UDESC (2007); Bacharel em MODA - Habilitação em Estilismo pela UDESC 2004); Professora nos cursos de Design de Moda da UDESC, Universidade Estácio de Sá - SC e Centro Universitário Leonardo da Vinci - UNIASSELVI.

fabiludwig@hotmail.com

\section{Schirlei Martins Ortega San Romãn}

Graduanda em Design Gráfico pela UDESC; cursando especialização em Ilustração na Universidade do Vale do Itajaí. Bacharel em Pedagogia.

schirlei.ortega@gmail.com 